\title{
Diagnóstico da Resistência aos Herbicidas em Plantas daninhas ${ }^{1}$
}

\author{
Diagnosis of Herbicide Resistance in Weeds
}

VIDAL, R.A. ${ }^{2}$, LAMEGO, F.P. ${ }^{3}$ e TREZZI, M.M. ${ }^{4}$

\begin{abstract}
RESUMO - A resistência de plantas daninhas aos herbicidas caracteriza-se como um fenômeno evolutivo, decorrente da seleção imposta por estes. Esse é um problema grave que vem aumentando nos últimos anos nas áreas agrícolas em todo o mundo. A prevenção por meio de métodos alternativos de manejo atrasa o aparecimento de plantas resistentes, porém o monitoramento periódico das lavouras é a melhor forma de evitar a disseminação quando do surgimento da resistência. Métodos diagnósticos rápidos, eficazes e precisos são úteis na confirmação dos casos de resistência, evitando a disseminação de sementes na área. Diversos métodos têm sido desenvolvidos nos últimos anos, buscando agilizar o diagnóstico da resistência. Recentemente, métodos desenvolvidos através do uso da biotecnologia têm sido aprimorados e mostram uma tendência para o futuro na detecção da resistência aos herbicidas pelas plantas daninhas. No presente trabalho, objetivou-se discutir os métodos para diagnóstico da resistência em plantas daninhas aos herbicidas relatados pela literatura, apresentando suas vantagens e desvantagens, bem como abordando suas possibilidades de aplicação.
\end{abstract}

Palavras-chave: biótipos resistentes, inibidores da ALS, inibidores da ACCase, glyphosate.

\begin{abstract}
Weed resistance to herbicides is an evolutive phenomenon caused by the selection imposed by the herbicides. This serious problem has been increasing in the last years in agricultural areas. Prevention through alternative management methods delays the appearance of resistant weeds. However, periodic monitoring of farmlands is the best way to avoid the spreading of the selected resistance biotypes. Fast, efficient and precise diagnosis methods are useful in the confirmation of resistance cases avoiding seed dissemination. Different methods have been developed in the last years seeking to improve resistance diagnosis. Recent methods developed through biotechnology have been improved and are promising methods for herbicide resistant weed detection.
\end{abstract}

Keywords: resistant biotypes, ALS inhibitors, ACCase inhibitors, glyphosate.

\section{INTRODUÇÃO}

A adoção do controle químico, por meio do uso de herbicidas, representou um avanço nas técnicas de manejo de plantas daninhas. No Brasil, em média, de todos os produtos fitossanitários utilizados nas lavouras agrícolas, 56\% são herbicidas, aproximando-se da média mundial de 48\% (Grimes, 1998). No entanto, após anos consecutivos do uso desses produtos, deparou-se com o aparecimento de muitos casos de resistência a tais compostos por diversas espécies daninhas.

Atualmente, existem mais de 300 biótipos resistentes aos herbicidas no mundo, envolvendo 181 espécies daninhas (Heap, 2005). Dada a importância do controle das plantas

Recebido para publicação em 21.3.2006 e na forma revisada em 4.8.2006.

2 Eng.-Agr., Ph.D., Professor da Universidade Federal do Rio Grande do Sul - UFRGS, Caixa Postal 15.100, 90000-970 Porto Alegre-RS, bolsista do CNPq, <ribas.vidal@ pesquisador.cnpq.br>; ${ }^{3}$ Eng.-Agr., M.S., doutorando do Programa de Pós-Graduação em Fitotecnia da UFRGS, bolsista do CNPq, <fabilamego@yahoo.com.br>; ${ }^{4}$ Eng.-Agr., Dr., Prof. da Universidade Federal Tecnológica do Paraná, Caixa Postal 571, 85503-390 Pato Branco-PR, <trezzi@ pb.cefetpr.br>. 
daninhas, para que sejam garantidos elevados níveis de produtividade, a falha deste pode comprometer drasticamente a produção dos cultivos agrícolas, além de proporcionar aumento nos custos de produção. Dessa forma, a resistência de plantas daninhas aos herbicidas assume grande importância, principalmente em razão do limitado, ou inexistente, número de herbicidas alternativos para serem usados no controle dos biótipos resistentes. O número de ingredientes ativos disponíveis para controle de algumas espécies daninhas é bastante restrito, e o desenvolvimento de novas moléculas é difícil e oneroso. Portanto, diagnosticar a resistência em uma população de plantas daninhas de forma rápida, eficaz e precisa ajuda a prevenir a disseminação de sementes resistentes na área, evitando problemas futuros.

Mundialmente, têm sido desenvolvidos diversos métodos para diagnosticar a resistência em várias espécies daninhas (Vidal \& Merotto Jr., 1999; Boutsalis, 1999; Eleftherohorinos et al., 2000; Tuesca \& Nisensohn, 2001; Delye et al., 2002; Siminszky et al., 2005). Alguns métodos mostram-se mais vantajosos para determinadas situações em que, por exemplo, há limitação de recursos; já outros são mais sofisticados e requerem mãode-obra especializada. O importante é que sejam precisos e garantam a certificação de resistência ou não a determinado grupo herbicida. Esta revisão tem por objetivo discutir os métodos diagnósticos para a resistência em plantas daninhas aos herbicidas relatados pela literatura, apresentando suas vantagens e desvantagens e abordando possibilidades de sua aplicação.

\section{ESTUDOS DE DIAGNÓSTICO}

O diagnóstico de resistência de plantas daninhas aos herbicidas pode ser feito a partir de duas formas de estudo: in vivo ou in vitro. Os testes in vivo podem ser realizados diretamente no campo ou em casa de vegetação. No campo, existe a desvantagem de não se ter testemunha suscetivel e de não ser prudente utilizar doses muito além das indicadas em rótulo. Já para os testes em casa de vegetação, coletam-se no campo sementes de plantas suspeitas de resistência e também daquelas conhecidamente não-resistentes. Estas sementes são semeadas em vasos e cultivadas em casa de vegetação; após a emergência das plantas, elas serão tratadas com diferentes doses, sendo comparado o desempenho do herbicida nas populações sob teste (Gazziero et al., 1998; Vidal \& Merotto Jr., 1999; Beckie et al., 2000).

Em experimento conduzido por Ryan (1970), sementes de Senecio vulgaris foram coletadas em duas áreas: uma suspeita de resistência e outra nunca antes aspergida com herbicidas. Posteriormente, as sementes foram conduzidas à casa de vegetação, onde foi desenvolvido protocolo para comprovação científica da resistência ao herbicida triazina. Através de aplicações de doses crescentes do herbicida, constatou-se a ausência de controle das plantas de Senecio por triazina. Também, sementes de Brachiaria plantaginea suspeitas de resistência foram colhidas no Paraná e testadas em casa de vegetação, sendo comprovada sua resistência aos herbicidas inibidores de ACCase (Gazziero et al., 2000). Em outro tipo de ensaio in vivo, foi avaliado o acúmulo de chiquimato em tecido foliar de plantas, visando detectar de forma rápida a resistência a glyphosate, uma vez, que após aplicação deste herbicida, ocorre o acúmulo de chiquimato pela inibição da enzima 5-enolpiruvilchiquimato-3fosfato sintase (EPSPS) (Shaner et al., 2005).

Testes in vivo realizados em diversos locais no Brasil (Gazziero et al., 1998; Vidal \& Trezzi, 1999; Gazziero et al., 2000) e no mundo (Pratley et al., 1999; Eleftherohorinos et al., 2000; Tuesca \& Nisensohn, 2001; Shaner et al., 2005) têm sido eficazes na constatação de resistência aos herbicidas. Além da possibilidade de teste de um grande número de plantas, não é necessário o uso de mão-deobra especializada na instalação dos testes envolvendo avaliações de dose-resposta aos herbicidas. Ensaios envolvendo o acúmulo de substratos como chiquimato na detecção de resistência a glyphosate, por exemplo, já exigem equipamentos sofisticados de laboratório, o que os tornam muitas vezes inviáveis. Como desvantagens destes testes in vivo destacamse a demora na obtenção dos resultados, a necessidade de as sementes não estarem dormentes e a elevada utilização de mão-de-obra e de material (Saari et al., 1994). Apesar disso, a metodologia de teste em casa de vegetação 
tem sido utilizada de forma indispensável na comprovação científica da resistência, complementando resultados de campo e de laboratório.

Testes realizados in vitro envolvem a extração da enzima-alvo da ação do herbicida (Ponchio, 1997), a avaliação do RNA ou DNA desta (Saari et al., 1994) ou, ainda, a avaliação de enzimas que fazem parte da rota de ação da enzima-alvo da ação dos herbicidas (Gerwick et al., 1993; Singh \& Shaner, 1998). Um exemplo a ser citado é o do uso do ácido ciclopropanodicarboxílico (CPCA), inibidor da enzima cetoácido reductoisomerase (KARI), que catalisa a reação seguinte à da enzima acetolactato sintase (ALS) na rota de síntese de aminoácidos. Na ausência de CPCA, KARI converte os substratos acetolactato e acetoidroxibutirato, resultantes da reação com a ALS, em 2,3-di-hydroxi-3-isovalerate e 2,3-dihydroxy-3-methylvalerate, respectivamente. Em plantas suscetíveis aos inibidores de ALS, quando CPCA é aplicado juntamente com o inibidor de ALS, não é observado o acúmulo de acetolactato, uma vez que a ALS é inibida pelo herbicida. No entanto, em plantas resistentes, a ALS insensível promove a sintese de acetolactato, que, por sua vez, acumula-se devido à inibição de KARI pelo CPCA (Christoffoleti, 2001).

Bioensaios in vitro com a enzima acetolactato sintase (ALS) extraída de biótipos resistentes e suscetíveis de Bidens pilosa demonstraram a insensibilidade de enzimas provenientes das plantas resistentes (Ponchio, 1997). Esse método tem como vantagem maior precisão no diagnóstico da resistência, porém apresenta a desvantagem de ser específico ao mecanismo de resistência sob análise.

Outros testes in vitro promovem a quantificação de enzimas metabolizadoras, quando o mecanismo de resistência envolver metabolização do herbicida (Reade \& Cobb, 2002), ou, ainda, marcadores moleculares são selecionados com o fim específico de indicar a resistência (SariGorla et al., 1996; Rutledge et al., 2000). No geral, esses testes normalmente são complexos e envolvem muitos reagentes ou equipamentos especializados, o que limita sua realização por público leigo. Como desvantagem adicional, eles são realizados com pouca quantidade de tecidos da planta, o que implica a utilização de poucos indivíduos, limitando o escopo do resultado obtido (Saari et al., 1994; Beckie et al., 2000).

Os métodos descritos até então, in vivo e in vitro, apresentam como desvantagem o elevado tempo para na sua realização. Por exemplo, no método in vivo realizado a partir de sementes, há necessidade de pelo menos 40 dias entre a semeadura e a determinação de resistência. No caso de o resultado ser negativo, ou seja, de não se confirmar resistência ao herbicida testado, o teste deve ser repetido para assegurar ao agricultor a inexistência de resultado "falso-negativo". Com isso, são mais 40 dias de espera para confirmação do resultado final. A morosidade da diagnose acarreta prejuízos à cultura devido à interferência das plantas daninhas resistentes, que não são controladas, e devido ao custo de herbicidas erradamente aspergidos na área (Boutsalis, 2001).

Para acelerar o processo de confirmação da resistência e obter resultado já na própria estação de crescimento da planta cultivada, Boutsalis (2001) desenvolveu um método teoricamente mais rápido. Esse método consiste em coletar plantas suspeitas de resistência, desfolhá-las, podar drasticamente as raízes e enviá-las ao local onde serão plantadas em vaso. Após período de aclimatação e desenvolvimento de novas raízes e folhas, aproximadamente 20 dias, aplicam-se os herbicidas de interesse e aguarda-se período de cerca de 15 dias para confirmação da resistência. A grande vantagem desse método é que a confirmação da resistência poderá ser realizada já na própria estação de crescimento em que se coletaram as plantas. Contudo, note-se que o intervalo de tempo requerido para confirmação da resistência não é drasticamente afetado em relação ao procedimento antes descrito - cerca de 35 dias.

Outro método desenvolvido para diagnóstico da resistência aos herbicidas com experimentos de resposta à dose foi realizado com plântulas, as quais, posteriormente, após imersão na solução herbicida, foram colocadas em água (Portes, 2005). Quatro dias foi período suficiente para identificar sintomas em plantas suscetiveis aos inibidores de ALS e ACCase. As espécies avaliadas foram Eleusine indica, para resistência aos inibidores de ACCase, e 
Bidens pilosa e Euphorbia heterophylla, para os inibidores de ALS. Além da rapidez, outro benefício do método é sua facilidade de execução (Portes, 2005).

\section{Métodos alternativos para diagnosticar a resistência}

Outros testes para diagnóstico rápido da resistência de plantas daninhas aos herbicidas têm sido desenvolvidos pela comunidade científica, como informa revisão de literatura realizada por Beckie et al. (2000). Richter \& Powles (1993) publicaram um método que utiliza o crescimento de pólen em meio de cultura contendo o herbicida do qual se suspeita resistência. Igualmente, a resistência de Alopecurus myosuroides aos herbicidas inibidores de ACCase foi detectada pelo método do desenvolvimento do pólen em meio de cultura (Letouze \& Gasquez, 1999; Letouze \& Gasquez, 2000). Embora o método seja eficiente, ele demanda tempo para o florescimento das plantas a fim de obter o pólen, além de requerer maior habilidade do coletor do que simplesmente a coleta de sementes.

Discos foliares de determinadas espécies flutuam quando em solução com fosfato contendo surfatante. Isso ocorre porque a fotossintese está ativa. Folhas que flutuam na referida solução, quando posicionadas no escuro ou quando se adicionam herbicidas inibidores da fotossíntese ao meio, submergem (Truelove et al., 1974). Com base nesse princípio, foi desenvolvido método para detectar resistência às triazinas envolvendo as espécies Chenopodium album e Amaranthus hybridus. Discos foliares destas espécies foram colocados em tubos com solução herbicida e sob vácuo. Após infiltrarem a solução, os discos foliares submergem ao fundo dos tubos. O vácuo é então liberado, uma solução bicarbonato adicionada e os tubos são colocados na luz. Na situação em que a fotossíntese não foi inibida pelo herbicida, ou seja, no disco oriundo de biótipo resistente, o oxigênio fotossinteticamente gerado permite que o disco foliar volte a flutuar. Contudo, os discos oriundos de biótipos suscetiveis às triazinas permanecem no fundo do tubo (Hensley, 1981).

Outro método desenvolvido para economizar tempo e espaço em casa de vegetação/ laboratório no diagnóstico da resistência foi o da germinação de sementes em placas de Petri, contendo diversas concentrações de herbicida. Assim, esse diagnóstico pode ser feito em apenas cinco dias após exposição de Setaria viridis a diversas doses de trifluralin (Beckie et al., 1990). Esse tipo de teste também foi realizado para detectar resistência aos herbicidas inibidores das enzimas ACCase e ALS e também a glyphosate (Beckie et al., 2000; Tal et al., 2000; Escorial et al., 2001; Perez \& Kogan, 2003).

A resistência ao herbicida triallate foi detectada em biótipo de Avena fatua em apenas oito dias após o início do teste em placa de Petri (O`Donovan et al., 1996). Pelo mesmo método foi detectada, em apenas cinco dias, a resistência em biótipos de Avena fatua aos herbicidas inibidores de ACCase, como fenoxaprop-ethyl e sethoxydim (Murray et al., 1996). Kim et al. (2000) utilizaram o método da germinação de sementes para diagnosticar a resistência de Echinochloa colonum aos herbicidas fenoxaprop-ethyl e propanil. Uma adaptação do método da germinação das sementes, acrescentando-se giberelina na placa de Petri, também mostrou ser uma boa técnica para diagnóstico de resistência de Papaver rhoeas ao herbicida tribenuron (Cirujeda et al., 2001). Novamente, há necessidade, neste tipo de teste, da espera pela produção de sementes pelas plantas para, então, ser realizado o diagnóstico da resistência.

Recentemente, foi desenvolvido teste que utiliza a técnica de anticorpos monoclonais para detectar a presença da enzima glutationa transferase, a qual pode ser utilizada como marcadora da resistência de Alopecurus myosuroides aos herbicidas (Reade \& Cobb, 2002). Esse teste tem demonstrado ser rápido, de fácil utilização, de custo relativamente baixo e eficiente no diagnóstico de plantas resistentes, porém o desenvolvimento do método é demorado, envolve a necessidade de grande equipe multidisciplinar e requer consideráveis recursos financeiros para elaboração de todas as etapas da pesquisa.

\section{Detecção de resistência através da fotossintese}

Um dos métodos mais simples para detectar a ação dos herbicidas envolve a 
fotossintese. O monitoramento dos niveis de fluorescência nas plantas suspeitas de resistência e nas suscetiveis permite diagnosticar a resistência. Herbicidas que afetam o fluxo de elétrons no fotossistema II (FS2) permitem diagnóstico da resistência por meio de seus efeitos na fotossíntese ou na fluorescência das plantas. Assim, plantas resistentes a esses herbicidas têm sido diagnosticadas com precisão. Por exemplo, Alopecurus myosuroides resistente ao herbicida chlorotoluron mostrou boa recuperação dos niveis normais de fluorescência com o decorrer do tempo, enquanto plantas suscetiveis não demonstraram recuperação (Vanoorschot \& Vanleeuwen, 1992). Da mesma forma, a medida da fluorescência foi utilizada para diagnóstico da resistência de Datura stramonium aos herbicidas inibidores do FS2 (Vidal et al., 1993). Embora tenham mostrado precisão na confirmação da resistência aos inibidores de FS2, medições de variáveis fotossintéticas não foram bem sucedidas para diagnóstico de plantas resistentes aos herbicidas que atuam em outros locais, que não a fotossíntese (Goulart et al., 2004).

\section{Método molecular para detecção da resistência}

Com o advento da biologia molecular, trabalhos têm sido realizados utilizando técnicas moleculares a partir do DNA, que também permitem otimizar o tempo na confirmação da resistência quando esta ocorre por mecanismo de ação alterado, ou seja, mutação no sítio de ação (Délye et al., 2002; Corbett \& Tardif, 2006). No entanto, há necessidade de conhecimento prévio da mutação ocorrida no gene responsável pelo local de ação herbicida e, a partir de reação de PCR (reação em cadeia de polimerase), é possivel obter a confirmação da resistência ou não ao herbicida, trabalho que, em média, deve fornecer resultados muito mais rápidos que métodos clássicos de diagnóstico. Método diagnóstico molecular para resistência, denominado BASPCR, confirmou casos de resistência aos herbicidas inibidores de ACCase e inibidores da polimerização da tubulina em tempo previsto de uma semana, quando comparado a métodos clássicos, que podem levar 45 dias ou mais (Délye et al., 2004).
Embora a otimização de tempo seja importante, uma das grandes vantagens de métodos diagnósticos baseados no DNA é que mutações geradas por genes recessivos também podem ser detectadas, assim como aquelas dominantes, fato que não ocorre em bioensaios com plantas heterozigotas, uma vez que a aplicação do herbicida elimina o resistente recessivo da população.

Na espécie Ambrosia trifida, dois fragmentos de DNA isolados mostraram que a mutação de triptofano para leucina na posição 574 do gene de ALS, conforme ALS de Arabidopsis thaliana, foi a responsável pela resistência ao herbicida cloransulam. A partir dessa informação, primers específicos foram desenhados para promoverem amplificações na região do gene onde foi identificada a mutação (Patzoldt \& Tranel, 2002). Um conjunto de seis primers baseados em seqüências de ALS depositadas no GenBank permitiu obter a seqüência do gene de ALS para Amaranthus retroflexus, onde foi observado que as mutações de $\mathrm{Ala}_{122}$ para Thr, Ala ${ }_{205}$ para Val e Trp Tr4 $_{57}$ para Leu foram as responsáveis por diferentes padrões de resistência dos biótipos aos herbicidas (McNaughton et al., 2005). Trabalho mais recente, utilizando $\mathrm{PCR}$ e cromatografia líquida de alta performance, demonstrou sucesso na detecção de mutações no gene de ALS (Siminszky et al., 2005).

Para outros casos de resistência, como aos inibidores da enzima ACCase, ferramentas moleculares também têm auxiliado no diagnóstico; um PCR alelo-específico foi desenvolvido para detectar, com apenas um dia de trabalho, uma substituição de isoleucina por leucina no gene codificando para ACCAse, nas espécies Alopecurus myosuroides e Lolium rigidum (Délye et al., 2002). Ensaios bioquímicos comprovaram, através de PCR, que a resistência de biótipos da espécie Phalaris paradoxa ao herbicida inibidor de ACCase diclofop-methyl era devida à alteração no local de ação. Uma mutação de glicina para serina na posição 2096 da enzima ACCase confere resistência ao herbicida diclofop-methyl. A partir dessa informação, foi desenvolvido ensaio que utiliza PCR (PASA, PCR-based assay specific allele) para identificar a resistência aos inibidores de ACCase em plantas individuais (Ruiz-Santaella et al., 2006). 
Estudos de otimização de primers degenerados para clonagem de domínios da enzima ALS vêm sendo realizados e já permitiram seqüenciamento parcial do gene de ALS para a espécie Bidens pilosa (Prado et al., 2004). Contudo, o seqüenciamento dos cinco domínios do gene da enzima permitirá o desenvolvimento de método diagnóstico rápido da resistência, via técnica molecular.

\section{Detecção precoce da resistência em nivel de propriedade}

Na ciência das plantas daninhas existe um dogma de que os agricultores, normalmente, constatam a presença de plantas daninhas resistentes em suas lavouras apenas quando, aproximadamente, 30\% da comunidade infestante da espécie na área é formada por biótipos resistentes (LeBaron \& Gressel, 1982). Esse fato leva a conseqüências drásticas, permitindo o aumento no banco de sementes no solo, o que poderá implicar problemas mais sérios, devido à prolificidade da espécie daninha, à longevidade e à dormência de suas sementes. Como resultado, haverá maiores dificuldades para solucionar o problema.

Normalmente, o tempo para constatação da resistência e tomada de decisão com medidas de seu controle é demorado. Sementes/ plantas suspeitas de resistência coletadas nas propriedades são encaminhadas para os órgãos de pesquisa capacitados a realizar testes de diagnose de resistência aos herbicidas. Posteriormente, tenta-se convencer o agricultor a adotar métodos alternativos de manejo das plantas daninhas em geral, como rotação de culturas nas áreas, rotação de herbicidas, entre outros.

A detecção precoce da resistência através de monitoramento constante das lavouras permite colocar a área suspeita em quarentena e propicia a erradicação do biótipo selecionado. Em lavouras com áreas relativamente grandes e com elevado nivel de tecnologia podem-se realizar monitoramentos aéreos, observando "manchas" nas lavouras, as quais caracterizam plantas daninhas não controladas nas áreas, com posterior análise para detecção da resistência. Nas propriedades menores, pode-se acompanhar a evolução de plantas daninhas resistentes através de observação e detecção visual, eliminando as plantas que sobrarem nas áreas e evitando que produzam sementes. Quanto mais precoce a constatação de plantas resistentes na área, maior a probabilidade de poder empregar medidas preventivas à dispersão de sementes na lavoura, como quarentena, entre outros. O foco do trabalho deve ser a eliminação das infestações resistentes, enquanto a sua freqüência no banco de sementes no solo é reduzida e atingiu pequena extensão de terra (Tranel \& Wright, 2002).

\section{CONSIDERAÇÕES FINAIS}

A resistência de plantas daninhas aos herbicidas é um fenômeno evolutivo e que tem tido grande expressão nos últimos anos. A disponibilidade de método diagnóstico rápido, eficaz e preciso para detectar a resistência aos herbicidas permite a tomada de decisão correta e em tempo hábil para o manejo de plantas resistentes na área. Para isso, métodos clássicos testados em casa de vegetação estão prontamente disponiveis e ainda são bastante utilizados. Contudo, aqueles baseados na biotecnologia apresentam-se promissores para o futuro na detecção da resistência de plantas daninhas aos herbicidas. Aliada à identificação da resistência, a detecção precoce da população resistente ainda nos estádios iniciais da colonização da área, por meio de monitoramento constante das lavouras, provavelmente prevenirá a disseminação da resistência na área, evitando o incremento do banco de sementes do solo e, conseqüentemente, reduzindo os custos e o impacto do manejo desses biótipos.

\section{LITERATURA CITADA}

BECKIE, H. J. et al. A rapid bioassay to detect trifluralinresistant green foxtail (Setaria viridis). Weed Technol., v. 4, n. 3, p. 505-508, 1990.

BECKIE, H. J. et al. Screening for herbicide resistance in weeds. Weed Technol., v. 14, n. 2, p. 428-445, 2000.

BOUTSALIS, P. Syngenta quick-test: a rapid whole-plant test for herbicide resistance. Weed Technol., v.15, n. 2, p. 257-263, 2001.

BOUTSALIS, P.; KAROTAM, J.; POWLES, S. Molecular basis of resistance to acetolactate synthase-inhibiting herbicides in Sisymbrium orientale and Brassica tournefortii. Pest. Sci., v. 55, n. 5, p. 507-516, 1999. 
CHRISTOFFOLETI, P. J. Bioensaio para determinação da resistência de plantas daninhas aos herbicidas inibidores da enzima ALS. Bragantia, v. 60, n. 3, p. 261-265, 2001.

CIRUJEDA, A.; RECASENS, J.; TABERNER, A. A qualitative quick-test for detection of herbicide resistance to tribenuron-methyl in Papaver rhoeas. Weed Res., v. 41, n. 6, p. $523-534,2001$.

CORBETT, C. A. L.; TARDIF, F. J. Detection of resistance to acetolactate synthase inhibitors in weeds with emphasis on DNA-based techniques: a review. Pest Manag. Sci., v. 62, n. 7, p. 584-597, 2006.

DÉLYE, C. et al. Molecular tools for the diagnosis of targetsite-based of resistance of grass weeds to herbicides in groups A and K1. In: COLLOQUE INTERNATIONAL SUR LA BIOLOGIE DES MAUVAISES HERBES, 12., 2004, Dijon. Colloque..., Dijon: 2004. p. 581-588.

DÉLYE, C.; MATÉJICEK, A.; GASQUEZ, J. PCR-based detection of resistance to acetyl-CoA carboxylase-inhibiting herbicides in black-grass (Alopecurus myosuroides Huds) and ryegrass (Lolium rigidum Gaud). Pest Manag. Sci., v. 58, n. 5, p. 474-478, 2002.

ELEFTHEROHORINOS, I. G.; VASILAKOGLOU, I. B.; DHIMA, K. V. Metribuzin resistance in Amaranthus retroflexus and Chenopodium album in Greece. Weed Sci., v. 48, n. 1, p. 69-74, 2000.

ESCORIAL, M. C. et al. A rapid method to determine cereal plant response to glyphosate. Weed Technol., v. 15, n. 4, p. 697-702, 2001.

GAZZIERO, D. L. P. et al. Resistência de amendoim-bravo aos herbicidas inibidores da enzima ALS. Planta Daninha, v. 16, n. 2, p. 117-126, 1998.

GAZZIERO, D. L. P. et al. Resistência da planta daninha capim-marmelada (Brachiaria plantaginea) aos herbicidas inibidores da enzima ACCase na cultura da soja. Planta Daninha, v. 18, n. 1, p. 169-180, 2000.

GERWICK, B. C.; MIRELES, L. C.; EILERS, R. J. Rapid diagnosis of ALS AHAS-resistant weeds. Weed Technol., v. 7, n. 2, p. 519-524, 1993.

GOULART, I. C. G. R. et al. Diagnose da resistência aos inibidores de ALS em Bidens pilosa com fluorescência da clorofila. In: SALÃO DE INICIAÇÃO CIENTÍFICA, 6., 2004, Porto Alegre. Resumos... Porto Alegre: Universidade Federal do Rio Grande do Sul, 2004. p. 194.

GRIMES, A. World agrochemical markets. Richmond: Agrow, 1998. $170 \mathrm{p}$.

HEAP, I. International survey of herbicide resistant weeds. Disponível em: 〈http://www.weedscience.com>. Acesso em: 30 ago. 2005.
HENSLEY, J. R. A method for identification of triazine resistant and susceptible biotypes of several weeds. Weed Sci., v. 29, n. 1, p. 70-73, 1981.

KIM, D. S. et al. Rapid detection of propanil and fenoxaprop resistance in Echinochloa colona. Weed Sci., v. 48, n. 6, p. 695-700, 2000.

LeBARON, H. M.; GRESSEL, J. Herbicide resistance in plants. New York: John Wiley \& Sons, 1982. 401 p.

LETOUZE, A.; GASQUEZ, J. A rapid reliable test for screening aryloxyphenoxy-propionic acid resistance within Alopecurus myosuroides and Lolium spp. Populations. Weed Res., v. 39, n. 1, p. 37-48, 1999.

LETOUZE, A.; GASQUEZ, J. A pollen test to detect ACCase target-site resistance within Alopecurus myosuroides populations. Weed Res., v. 40, n. 2, p. 151-162, 2000.

McNAUGHTON, K. E. et al. Mutations in ALS confer herbicide resistance in redroot pigweed (Amaranthus retroflexus) and powell amaranth (Amaranthus powellii). Weed Sci., v. 53, n. 1, p. 17-22, 2005.

MURRAY, B. G. et al. A seed bioassay to identify acetyl-CoA carboxylase inhibitor resistant wild oat (Avena fatua) populations. Weed Technol., v. 10, n. 1, p. 85-89, 1996.

O'DONOVAN, J. T. et al. A seedling bioassay for assessing the response of wild oat (Avena fatua) populations to triallate. Weed Technol., v. 10, n. 4, p. 931-935, 1996.

PATZOLDT, W. L.; TRANEL, P. J. Molecular analysis of cloransulam resistance in a population of giant ragweed. Weed Sci., v. 50, n. 3, p. 299-305, 2002.

PEREZ, A.; KOGAN, M. Glyphosate-resistant Lolium multiflorum in Chilean orchards. Weed Res., v. 43, n. 1, p. 12-19, 2003.

PONCHIO, J. A. R. Resistência de Bidens pilosa L. aos herbicidas inibidores da enzima acetolactato sintase. 1997. 139 f. Tese (Doutorado em Agronomia) - Escola Superior de Agricultura "Luiz de Queiroz", Piracicaba, 1997.

PORTES, E. S. Eleusine indica (L.) Gaertn. resistente a alguns inibidores de ACCase e novo método para diagnóstico de plantas daninhas resistentes aos herbicidas. 2005. 85 f. Dissertação (Mestrado em Fitotecnia) Universidade Federal do Rio Grande do Sul, Porto Alegre, 2005.

PRADO, M. D.; De PRADO, R.; FRANCO, A. R. Design and optimization of degenerated universal primers for the cloning of the plant acetolactate synthase conserved domains. Weed Sci., v. 52, n. 4, p. 487-491, 2004.

PRATLEY, J. et al. Resistance to glyphosate in Lolium rigidum. I. Bioevaluation, Weed Sci., v. 47, n. 4, p. 405-411, 1999.

Planta Daninha, Viçosa-MG, v. 24, n. 3, p. 597-604, 2006 
READE, J. P. H.; COBB, A. H. New, quick tests for herbicide resistance in black-grass (Alopecurus myosuroides Huds) based on increased glutathione S-transferase activity and abundance. Pest Manag. Sci., v. 58, n. 1, p. 26-32, 2002.

RICHTER, J.; POWLES, S. B. Pollen expression of herbicide target site resistance genes in annual ryegrass (Loliumrigidum). Plant Physiol., v. 102, n. 3, p. 1037-1041, 1993.

RUIZ-SANTAELLA, J. P. et al. Detection of a new mutation of glycine to serine in the ACCase of a resistant biotype of Phalaris paradoxa. In: ANNUAL MEETING OF THE WEED SCIENCE SOCIETY OF AMERICA, 46., 2006, New York. Abstracts... New York: WSSA, 2006. p. 93.

RUTLEDGE, J.; TALBERT, R. E.; SNELLER, C. H. RAPD analysis of genetic variation among propanil-resistant and susceptible Echinochloa crus-galli populations in Arkansas. Weed Sci., v. 48, n. 6, p. 669-674, 2000.

RYAN, G. F. Resistance of common groundsel to simazine and atriazine. Weed Sci., v. 18, n. 5, p. 614-620, 1970.

SAARI, L. L.; COTTERMAN, J.C.; THILL, D.C. Resistance to acetolactate synthase inhibiting herbicides. In: POWLES, S.B.; HOLTUM, J.A.M. (Eds.). Herbicide resistance in plants: biology and biochemistry. Boca Raton: CRC Press, 1994. $353 \mathrm{p}$.

SARIGORLA, M. et al. Identification of genetic factors for alachlor tolerance in maize by molecular markers analysis. Molec. General Genetics, v. 251, n. 5, p. 551-555, 1996.

SHANER, D. L. et al. A rapid in vivo shikimate accumulation assay with excised leaf discs. Weed Sci., v. 53, n. 6, p. 769-774, 2005.

SIMINSZKY, B. et al. Denaturing high-performance liquid chromatography efficiently detects mutations of the acetolactate synthase gene. Weed Sci., v. 53, n. 2, p. 146-152, 2005.
SINGH, B. K.; SHANER, D. L. Rapid determination of glyphosate injury to plants and identification of glyphosateresistant plants. Weed Technol., v. 12, n. 3, p. 527-530, 1998.

TAL, A.; KOTOULA-SYKA, E.; RUBIN, B. Seed-bioassay to direct grass weeds resistant to acetyl coenzyme A carboxylase inhibiting herbicides. Crop Protec., v. 19, n. 7, p. 467-472, 2000.

TRANEL, P. J.; WRIGHT, T. R. Resistance of weeds to ALS-inhibiting herbicides: what have we learned? Weed Sci., v. 50, n. 6, p. 700-712, 2002.

TRUELOVE, B.; DAVIS, D. E.; JONES, L. R. A new method for detecting photosynthesis inhibitors. Weed Sci., v. 22 , n. 1 , p. $15-17,1974$.

TUESCA, D.; NISENSOHN, L. Resistance of Amaranthus quitensis to imazethapyr and chlorimuron-ethyl. Pesq. Agropec. Bras., v. 36, n. 4, p. 601-606, 2001.

VANOORSCHOT, J. L. P.; VANLEEUWEN, P. H. Use of fluorescence induction to diagnose resistance of Alopecurusmyosuroides Huds (black-grass) to chlorotoluron. Weed Res., v. 32, n. 6, p. 473-482, 1992.

VIDAL, R. A. et al. Efeito de metanol e atrazine em Datura stramonium resistente ao herbicida. In: CONGRESSO BRASILEIRO DE HERBICIDAS E PLANTAS DANINHAS, 19., 1993, Londrina. Resumos... Londrina: SBHPD, 1993. p. 302-303.

VIDAL, R. A.; MEROTTO JR., A. Resistência de amendoim-bravo (Euphorbia heterophylla L.) aos herbicidas inibidores da enzima acetolactato sintase. Planta Daninha, v. 17 , n. 3, p. 367-374, 1999.

VIDAL, R. A.; TREZZI, M. M. Desenvolvimento comparativo entre biótipos de leiteira (Euphorbia heterophylla). R. Bras. Agroc., v. 5, n. 1, p. 122-126, 1999. 